\title{
Asymptomatic pharyngeal carriage rate of Streptococcus pyogenes, its associated factors and antibiotic susceptibility pattern among school children in Hawassa town, southern Ethiopia
}

\author{
Asrat Anja ${ }^{1}$, Getenet Beyene ${ }^{2}$, Zewdineh S/Mariam² ${ }^{2}$ and Deresse Daka ${ }^{3^{*}} \mathbb{0}$
}

\begin{abstract}
Objectives: The aim of this study was to determine the asymptomatic pharyngeal carriage rate of S. pyogenes, antimicrobial pattern and related risk factors among school children in Hawassa, southern Ethiopia.

Results: Out of 287 school children's screened, 35 (12.2\%) were colonized with S. pyogenes. The carriage rate was significantly associated with factors such as sex (female $p=0.013$ ) occupational status of mother $(p=0.002)$, lower income source (500-900 ETB, 1000-1500 ETB) $(p=0.001$, and $p=0.042)$, history of hospitalization $(p=0.00)$ and residence of the children $(p=0.002)$. High level resistant to tetracycline and low level to vancomycin were observed, while penicillin, amoxicillin, erythromycin, chloramphenicol, and ceftriaxone were found to be effective.
\end{abstract}

Keywords: S. pyogenes, Nasopharyngeal carriage, Hawassa

\section{Introduction}

Streptococcus pyogenes (S. pyogenes) is a species of gram positive, aerotolerant, beta-hemolytic bacterium in the genus Streptococcus. It is classified as Lancefield Group A Streptococcus (GAS). S. pyogenes has continued as a significant human pathogenic organism for centuries. It causes a several diseases in humans including mild skin disease, upper respiratory tract (URT) infections, severe life-threatening conditions such as Rheumatic fever, glomerulonephritis, septicemia, pneumonia and streptococcal toxic shock syndrome [1].

Infection begins with colonization of the URT or injured skin surfaces. All age group may carry GAS on throat and epidermis of skin, however, children aged

*Correspondence: drsdk200@gmail.com

${ }^{3}$ Hawassa University College of Medicine and Health Sciences, Hawassa, Ethiopia

Full list of author information is available at the end of the article
5-15 years old are a major reservoir of pharyngeal carriage of GAS [2].

GAS is highly communicable and can cause disease in individuals of all ages. School-age children (5-15 years) are considered as the major reservoir of GAS, with a prevalence of $2.5-25 \%$ or more depending on the study setting [3]. In Ethiopia, the asymptomatic carriage rate of GAS among healthy school children was $9.7-16.9 \%[4,5]$.

An educational status, employment status of the family, separation of mother and father [6], sex [7-10], socioeconomic and environmental factors, lack of awareness of disease transmission are the risk factor for colonization of the S. pyogenes among school children [11, 12].

GAS has not been developed resistance to any of the penicillin's over the last decades. Nowadays, it is starting to appear antimicrobial drug resistant strain from asymptomatic children [13] including penicillin [6]. However, in Ethiopia, antimicrobial resistance pattern to the GAS isolated from throat/phalanx were not adequately explicated. Therefore, the present study was aimed to 
determine the carriage rate of S. pyogenes, associated risk factors and antibiotic susceptibility pattern among school children in Hawassa, South Ethiopia, 2018.

\section{Main text \\ Methods \\ Study area and period}

Hawassa is the capital city of the Southern Nation Nationalities and people's Government. It is located $275 \mathrm{~km}$ South of Addis Ababa, and has an altitude of $1665 \mathrm{~m}$ above sea level with mean annual temperature and rainfall of $20.9^{\circ} \mathrm{C}$ and $997.6 \mathrm{~mm}$, respectively.

\section{Study design}

A school based cross-sectional study design was conducted from May to October 2018 in Hawassa, South Ethiopia.

\section{Source population}

All school children who attached governmental primary schools found in Hawassa town during the study period.

\section{Inclusion criteria}

All children aged 5-15 years who attend the class in selected schools during the study period and children whose parents had accepted the consent to participate in the study.

\section{Exclusion criteria}

All children who were on antibiotics for the last 2 weeks those with any signs and symptoms of respiratory diseases such as fever, soreness and throat, cough and watery nasal discharge were excluded.

\section{Study population}

A total of 295 school children were enrolled in this study. The study participants were selected by using a multistage stratified sampling technique. From the total of 19 governmental primary schools 30\% (5 of the schools) were included. Simple random sampling technique was used to select the schools. Proportionate amount of samples were assigned to each selected schools. Then study participants were identified by the lists of students using simple random sampling technique.

\section{Specimen collection}

The sample was collected from different school children from May to October 2018. The schools were sampled at the same period of time. All the swabs were immediately transferred to Amies transport medium (Oxoid, UK). Each sample was labeled very well. Within $2 \mathrm{~h}$ the collected swab were transported to the Microbiology laboratory $[9,14,15]$.

\section{Isolation of GAS}

The throat swabs were directly inoculated to $5 \%$ sheep blood agar plates (Blood agar base, Oxoid UK) by rolling the swab over a small area of the plate and streaking the sample using a sterile loop and incubated at $37^{\circ} \mathrm{C}$ with $5 \% \mathrm{CO}_{2}$ atmosphere and examined beta-haemolytic colonies after $24 \mathrm{~h}$ and $48 \mathrm{~h}$. Beta-haemolytic streptococci were identified by their colony morphology and beta-haemolysis.

All plates with beta-haemolytic colonies were subcultured with 0.04 U Bacitracin disks (Oxoid, UK) in blood agar plates similar manner as an earlier. All grams positive, catalase negative and any zone of inhibition around the disk were candidate for Pyrrolidonyl arylamidase (PYR) tests. A purple color in PYR tests were identified as $S$. pyogenes according to publications [16-18].

\section{Antimicrobial susceptibility testing}

Antibiotic susceptibility test (AST) was performed on disc diffusion method for all S. pyogenes using penicillin (10 U), erythromycin $(15 \mu \mathrm{g})$, amoxicillin $(10 \mu \mathrm{g})$, chloramphenicol $(30 \mu \mathrm{g})$, ceftriaxone $(30 \mu \mathrm{g})$, vancomycin $(30 \mu \mathrm{g})$ and tetracycline $(10 \mu \mathrm{g})$.

\section{Data management and quality control}

Quality of the data was ensured by using pre-structure questionnaire. For laboratory analysis the sterility of the prepared media was checked by incubating $5 \%$ by of prepared with in $5 \% \mathrm{CO}_{2}$ enriched atmosphere at $37^{\circ} \mathrm{C}$ for $24 \mathrm{~h}$ before using it. A quality control strain of $S$. pyogenes (ATCC19615) was used a positive control for each test.

\section{Data processing and analysis}

Data entry and analysis was performed by using SPSS version 20. The frequency of variables the prevalence of $S$. pyogenes, and antibiotic susceptibility pattern was determined. The association between risk factors and $S$. pyogenes colonization was determined by using logistic regression. A $p$ value $<0.05$ at $95 \%$ confidence interval (CI) was considered statistically significant.

\section{Result}

\section{Socio-demographic characteristics}

Out of 295 school children who participated in the present study, 147 (51.2\%) were males, $250(87.8 \%)$ were within the age of $5-12$ years. About $41.8 \%$ of the study participant's parents/guardian found to have no formal education. A fifty percent of students' mothers were a house-wife. About 162 (56.4\%) of a total children's parents/guardian had a monthly income between 500 
Table 1 Antimicrobial susceptibility pattern of S. pyogens isolated from school children at Hawassa city from May to October $2018(n=35)$

\begin{tabular}{lll}
\hline Antimicrobial agents & Resistant $\mathbf{n}(\%)$ & Susceptible n (\%) \\
\hline Penicillin & $0(0.0 \%)$ & $35(100 \%)$ \\
Vancomycin & $9(25.7 \%)$ & $26(74.3 \%)$ \\
Erythromycin & $1(2.9 \%)$ & $34(97.1 \%)$ \\
Chloramphenicol & $1(2.9 \%)$ & $34(97.1 \%)$ \\
Ceftriaxone & $1(2.9 \%)$ & $34(97.1 \%)$ \\
Amoxicillin & $1(2.9 \%)$ & $34(97.1 \%)$ \\
Tetracycline & $20(57.1 \%)$ & $15(42.9 \%)$ \\
\hline
\end{tabular}

Table 2 The predominant multiple antibiotic resistant phenotypes for $S$. pyogenes isolated from school children at Hawassa city from May-October 2018 ( $n=24)$

\begin{tabular}{lc}
\hline Phenotypes & $\begin{array}{l}\text { Isolates } \\
\text { tested N } \\
\text { (\%) }\end{array}$ \\
\hline Tetracycline & $13(54.2)$ \\
Vancomycin & $4(16.7)$ \\
Tetracycline, amoxicillin & $1(4.2)$ \\
Tetracycline, ceftriaxone & $1(4.2)$ \\
Tetracycline, vancomycin & $4(16.7)$ \\
Tetracycline, vancomycin, erythromycin & $1(4.2)$ \\
\hline
\end{tabular}

and 900 ETB, 33 (11.5\%) had 1000-1500 ETB and 92 (32.1\%) had higher than 1500 ETB per month. However, the average income source of this area was 1560.00 ETB.

\section{The prevalence of S. pyogenes}

Among 287 school children 35 (12.2\%) 95\% CI [19-27.8] were confirmed to have $S$. pyogenes in throat swabs. A colonization rate of $S$. pyogenes among children who were 5-8 years old, 9-12 years old, 13-15 years old, those who live with employed mother, those who live with poor income source were 12 (17.1\%), 18 (10.0\%), 5 (13.5\%), 8 (17.0\%), and $26(16 \%)$, respectively (Table 3$)$.

The prevalence of $S$. pyogenes was higher among children with employed mother 8 (17.0\%) than other occupations. Highest carriage rate was detected in low socioeconomic class 500-900 ETB per month 26 (16.0\%) followed by 1000-1500 ETB 4 (12.1\%). Among a total of 35 (12.2\%) S. pyogenes isolates, the highest carriage rate was observed in student's family size more than 5 person per house 23 (12.6\%).

Out of 35 S. pyogenes isolated in this study, 35 (100\%), $26(74.3 \%)$, and $15(42.9 \%)$ were susceptible to penicillin, vancomycin and tetracycline, respectively. About 34 (97.1\%) of $S$. pyogenes isolates were sensitive to erythromycin, chloramphenicol, ceftriaxone and amoxicillin (Tables 1 and 2).

\section{Risk factor analysis for pharyngeal carriage}

The possible risk factors such as age, sex, children living status, parents/guardians occupation, parents/guardians education, income of parents, family size, person per bed room sharing, and past history of recurrences of URTI were evaluated for pharyngeal carriage of S. pyogenes. It was observed in bivariate analysis that, female children $(\mathrm{COR}=2.212 ; 95 \%$ CI $1.055-0.638 ; \mathrm{p}=0.013)$, low income of parents $(\mathrm{COR}=3.326$; $95 \%$ CI $1.231-8.990$; $\mathrm{p}=0.001)$, children being with mother $(\mathrm{COR}=0.34 ; 95 \%$ CI 0.2-1.6; $\mathrm{p}=0.301$ ), and occupational status of mothers $(C O R=1.8(1.2-4.40) 95 \%$ CI 1.2-4.40; $\mathrm{p}=0.02$ were observed.

The female children $(\mathrm{AOR}=2.730$; 95\% CI 1.24-6.037; $\mathrm{p}=0.013)$, and low income of parents $(\mathrm{AOR}=11.917$; 95\% CI 2.729-2.032; $\mathrm{p}=0.001$ ) were associated with $S$. pyogenes carriage. Conversely, Occupational status of mothers (AOR $=100 ; 95 \%$ CI $0.023-0.437 ; \mathrm{p}=0.002)$ was associated with reduced likelihood of risk for asymptomatic pharyngeal carriage of S. pyogenes (Table 3).

\section{Discussion}

The overall asymptomatic pharyngeal carriage rate of S. pyogenes among school children was $12.2 \%$ which is higher than the reports in Ethiopia 9.7\% [4], in Tunisia $9.0 \%$ [19], in Nigeria 10\% [20], Pemba 8.6\% [21], India 8.4\% [12], and Mangalore 5\% [7] and lower than the report of Ethiopia 16.9\% [5], Turkey 13.9\% [22], Pennsylvania 15.9\% [11], Australia 19.5\% [23] and Turkey 25.9\% [15]. The possible explanation for the variation might be due to vaccination status and age differences. Moreover, sample size, seasonal variation and method if used, geography and socio-demographic variation are another possible explanation of the difference $[4,11,21,24]$.

In the present study we assessed different factors that could possibly increase colonization rate of $S$. pyogenes. Having female children 23 (16.4\%) were 2.21 times more risk than male children for $S$. pyogenes colonization $(p=0.013)$. Similar result was reported from India [6], Turkey [4] and Nepal [5] and Ethiopia [4, 11, 21, 24]. This is might be due to social attitude towards female children or high contact with the others during supporting their mother in daily tasks.

The detection rate of $S$. pyogenes were high in children who had illiterate parents 19 (15.8\%) ( $\mathrm{p}>0.05)$. It was inlined with study reveled in India 44.9\% [14], and in Iraqi $66.7 \%$ [25]. This might be reflects the literate parents had better awareness of the hygiene, hand washing and not sharing utensils than the illiterate parents. 
Table 3 Distribution and association of S. pyogenes among school children in Hawassa from May-October 2018

\begin{tabular}{|c|c|c|c|c|c|}
\hline \multirow[t]{2}{*}{ Variables } & \multicolumn{2}{|l|}{ Total S. pyogenes } & \multirow[t]{2}{*}{$\operatorname{COR}(95 \% \mathrm{Cl})$} & \multirow[t]{2}{*}{ Total $\mathrm{N}=\mathbf{2 8 7}(\mathbf{1 0 0 \% )}$} & \multirow[t]{2}{*}{ p value } \\
\hline & Present $n=35(12.2 \%)$ & Absent $\mathrm{n}=252(87.8 \%)$ & & & \\
\hline \multicolumn{6}{|l|}{ Sex } \\
\hline Female & $23(16.4)$ & $117(83.6)$ & 1 & $140(48.8)$ & 0.013 \\
\hline Male & $12(8.2)$ & $135(91.8)$ & $2.21(1.8-3.14)$ & $147(51.2)$ & \\
\hline \multicolumn{6}{|l|}{ Age } \\
\hline $5-8$ & $12(17.1)$ & $58(82.9)$ & $0.76(0.5-1.8$ & $70(24.4)$ & 0.123 \\
\hline $9-12$ & $18(10.0)$ & $162(90.0)$ & $1.41(0.8-3.20)$ & $180(62.7)$ & 0.626 \\
\hline $13-15$ & $5(13.5)$ & $32(86.5)$ & 1 & $37(12.9)$ & \\
\hline \multicolumn{6}{|c|}{ Children living status } \\
\hline With others ${ }^{\mathrm{a}}$ & $7(14.9)$ & $40(85.1)$ & $0.64(0.3-1.90)$ & $47(16.4)$ & 0.427 \\
\hline Mother only & $7(25.0)$ & $21(75.0)$ & $0.34(0.2-1.6)$ & $28(9.8)$ & 0.301 \\
\hline Father only & $0(0.0)$ & $4(100.0)$ & 0 & $4(1.4)$ & 0.264 \\
\hline Both parent & $21(10.1)$ & $187(89.9)$ & 1 & $208(72.5)$ & \\
\hline \multicolumn{6}{|c|}{ Educational status of parents } \\
\hline Illiterate & $19(15.8)$ & $101(84.2)$ & $0.89(0.5-2.20)$ & $120(41.8)$ & 0.365 \\
\hline $1-4$ & $1(5.0)$ & $19(95.0)$ & $3.2(1.8-4.80)$ & $20(6.7)$ & 0.309 \\
\hline $5-12$ & $10(8.9)$ & $102(91.1)$ & $1.7(0.9-2.6)$ & $112(39.0)$ & 0.546 \\
\hline$>12$ & $5(14.3)$ & $30(85.7)$ & 1 & $35(12.2)$ & \\
\hline \multicolumn{6}{|c|}{ Occupational status of mothers } \\
\hline Others $^{b}$ & $10(10.2)$ & $88(89.8)$ & $1.8(1.2-4.40)$ & $98(34.1)$ & 0.002 \\
\hline House wife & $17(12.0)$ & $125(88.0)$ & $1.5(0.7-3.20)$ & $142(49.5)$ & 0.002 \\
\hline Employed & $8(17.0)$ & $39(83.0)$ & 1 & $47(16.4)$ & \\
\hline \multicolumn{6}{|c|}{ Occupational status of fathers } \\
\hline Others $^{c}$ & $21(14.8)$ & $121(85.2)$ & $0.35(0.2-1.50)$ & $142(49.5)$ & 0.446 \\
\hline Farmer & $7(10.8)$ & $58(89.2)$ & $0.26(0.18-1.94)$ & $65(22.6)$ & 0.602 \\
\hline Employed & $7(8.8)$ & $73(91.2)$ & 1 & $80(27.9)$ & \\
\hline \multicolumn{6}{|l|}{ Family income } \\
\hline $500-900$ & $26(16.0)$ & $136(84.0)$ & $0.3(0.2-1.68)$ & $162(56.4)$ & 0.001 \\
\hline $1000-1500$ & $4(12.1)$ & $29(87.9)$ & $0.42(0.3-2.20)$ & $33(11.5)$ & 0.042 \\
\hline$>1500$ & $5(5.4)$ & $87(94.6)$ & 1 & $92(32)$ & \\
\hline \multicolumn{6}{|c|}{ Past history of recurrent of URTI/RHD } \\
\hline Yes & $6(14.6)$ & $35(85.4)$ & $0.78(0.6-1.70)$ & $41(14.3)$ & 0.607 \\
\hline No & $29(11.8)$ & $217(88.2)$ & 1 & $246(85.7)$ & \\
\hline \multicolumn{6}{|c|}{ Number of family per house } \\
\hline$<5$ & $12(12.5)$ & $84(87.5)$ & 1 & $96(33.4)$ & 0.208 \\
\hline$\geq 5$ & $23(12.0)$ & $168(88.0)$ & $10.9(4.0-22.0)$ & $191(66.6)$ & \\
\hline \multicolumn{6}{|l|}{ Residence } \\
\hline Urban & $16(22.9)$ & $54(77.1)$ & 1 & $70(24.4)$ & \\
\hline Rural & $19(8.8)$ & $198(91.2)$ & $3.1(1.7-5.8)$ & $217(75.6)$ & 0.002 \\
\hline \multicolumn{6}{|c|}{ Cooking in bed room } \\
\hline Yes & $10(7.0)$ & $133(93.0)$ & $2.79(1.2-6.4)$ & $143(49.8)$ & 0.321 \\
\hline No & $25(17.4)$ & $119(82.6)$ & 1 & $144(50.2)$ & \\
\hline \multicolumn{6}{|c|}{ Previous any disease } \\
\hline Yes & $25(12.8)$ & $170(87.2)$ & $0.83(0.6-2.1)$ & $195(67.9)$ & \\
\hline No & $10(10.9)$ & $82(89.1)$ & 1 & $92(32.1)$ & - \\
\hline \multicolumn{6}{|c|}{ History of hospitalization } \\
\hline Yes & $22(9.1)$ & $220(90.9)$ & $4.1(1.9-9.2)$ & $44(15.33)$ & 0.000 \\
\hline No & $13(28.9)$ & $32(71.1)$ & 1 & $45(15.7)$ & \\
\hline
\end{tabular}

Italic values indicate significance of $p$ value $(p<0.05)$

$R H D$ rheumatic heart disease, $A O R$ adjusted odds ratio, $C O R$ crude odds ratio

a Guardians/care givers, ${ }^{\text {b }}$ Both mother and father, ${ }^{\mathrm{C}}$ Daily labor, merchant, students 
There was clear association of pharyngeal carriage rate and children from low income families in our finding which 26 were (16.0\%). It was in accordance with the earlier finding in Ethiopia [5] and other studies carried out in many parts of the world [7, 25].

The carrier group of S. pyogenes was higher 10.9 times more among children living within families of more than 5 members than less family members in our study ( $\mathrm{p}>0.05$ ). Similarly, S. pyogenes carriage was significantly higher in large family size as reported in different authors $(p<0.05)[2,23,26]$. This might be an increasing the number of family members increases the rate of prevalence of many infectious diseases including GAS.

A Children with a history of hospital admission had 4.1 times chance to be colonized with GAS $(p=0.00)$ which is comparable to other's studies [27]. A children with history of recurrent pharyngitis show higher incidence $8(80 \%)$ of carrier than those with no history of pharyngitis 16 (17.8\%) [25].

A children from rural resident were 3 times $(p=0.002)$ more likely to have S. pyogenes carriage. This finding is similar to that the report found in Uganda at Wakiso district [28]. In the current study, a high proportion (12.8\%) of previously diseased children was colonized with S. pyogenes even though it was not statistically significant $(\mathrm{p}>0.05)$.

Out of 35 of S. pyogenes isolated in this study, 35 (100\%), 26 (74.3\%) and 15 (42.9\%) were susceptible to penicillin, vancomycin and tetracycline, respectively. However, 34 (97.1\%) of S. pyogenes were susceptible to erythromycin, ceftriaxone, chloramphenicol and amoxicillin. The finding is similar as compared with the report found in Ethiopia [4] and in different parts of the world [7-9, 12-14, 29-34]. About 7 (29.2\%) of isolated GAS strains were showed multiple drug resistant (two or more drugs). This is might be due to the ease of availability of antibiotics and misuse of the drugs.

\section{Conclusion}

The prevalence of S. pyogenes among school children in this study was high. The gender difference and low income of parents, residence of the children and occupational status of the mother are the prime risk factors associated with the carriage rate. All S. pyogenes isolates were susceptible to penicillin but most isolates were susceptible to chloramphenicol, Erythromycin and Ceftriaxone. Low level of resistant was observed against vancomycin and high level was observed against tetracycline. Further study in the area by using large sample size and all predisposing factors should be investigated.

\section{Limitation of the study}

Serotyping of Group A streptococci and ASO titer was not performed due to lack of antisera.

\section{Abbreviations}

ETB: Ethiopian birr; ATCC: American type culture control.

\section{Acknowledgements}

We would like to acknowledge data collector, all staff working at kindergarten school that facilitated data collection, Hawassa University College of Medicine and Health Sciences, Jimma University Health Science institute for their support during the study. We would also acknowledge parents who allowed their children to participate in this study.

\section{Authors' contributions}

AA: conceived and designed the study, performed the laboratory work, analyzed the data, involved in manuscript preparation. GB and ZS: involved in protocol development and manuscript write up. DD: conceived and designed the study, supervised the study, involved in analysis and manuscript preparation. All authors read and approved the final manuscript.

\section{Funding}

This study was supported by Jimma University, institute of Health Sciences. The support included payment for data collectors and purchase of materials and supplies required for the study. The support did not include designing of the study, analysis, and interpretation of data, and manuscript preparation.

\section{Availability of data}

The data used/analyzed during the current study available from the corresponding author on reasonable request.

\section{Ethics approval and consent to participate}

This study was ethically cleared from the Institutional Review Board (IRB) of the College of Medicine and Health Sciences, Hawassa University. Official permission was obtained from the study site and written informed consent was obtained from all parents/guardians of the children.

\section{Consent for publication}

Not applicable.

\section{Competing interests}

The authors declare that they have no competing interests.

\section{Author details}

${ }^{1}$ Dilla University College of Medicine, Dilla, Ethiopia. ${ }^{2}$ Jimma University Institute of Health Sciences, Jimma, Ethiopia. ${ }^{3}$ Hawassa University College of Medicine and Health Sciences, Hawassa, Ethiopia.

Received: 30 July 2019 Accepted: 3 September 2019

Published online: 10 September 2019

\section{References}

1. Ferretti JJ, Stevens DL, Fischetti VA, editors. Streptococcus pyogenes: basic biology to clinical manifestations. Oklahoma: The University of Oklahoma Health Sciences Center; 2016.

2. Saleh MMS. Carriage state of Gaßhs among Yemeni School children and the upper limit of Normal for ASO in different population groups. Iraqi J Sci. 2010;51(1):63-70.

3. Revelas A, Taxmazidis O. Group A streptococcal infections in children. S Afr J Epidemiol Infect. 2012;27(3):98-103.

4. Abdissa A, Asrat D, Kronvall G, Shitu B, Achiko D, Zeidan M, et al. Throat carriage rate and antimicrobial susceptibility pattern of Group A Streptococci (GAS) in healthy Ethiopian school children. Ethiop Med J. 2011;49(2):125-30. 
5. Tewodros W, Muhe L, Daniel E, Schalen C, Kronvall A. One-year study of streptococcal infections and their complications among Ethiopian children. Epidemiol Infect. 1992;109:211-25.

6. Nabipour F, Tayarzadeh M. Prevalence of beta-hemolytic streptococcus carrier state and its sensitivity to different antibiotics among guidanceschool children in Kerman-Iran. Am J Infect Dis. 2005;1(2):128-31.

7. Chand P, Arvind N, Vishrutha K, Vidyalakshmi K, Shenoy S. Surveillance of Group A Streptococcal throat infections among school children in Mangalore. Int J Biol Med Res. 2013;4(4):3585-9.

8. Muthusamy D, Boppe A, Suresh SP. The prevalence of the Group A beta haemolytic streptococcal carriers among school children in Coimbatore, South India. J Clin Diagn Res 2012;6(4).

9. Raza S, Kundu KK, Dutta SK. Prevalence of asymptomatic pharyngeal carriage of (3-hemolytic Group A Streptococcus pyogenes among school going children of age 5-12 years in Bharatpur, Nepal. J Kathmandu Med Coll. 2013;2(3):18-20.

10. Vijaya D, Sathish JV, Janakiram K. The prevalence of Group A Streptococci carriers among asymptomatic school children. J Clin Diagn Res. 2013;7(3):446-8

11. Martin JM, Green M, Barbadora KA, Wald ER. Group A Streptococci among school-aged children: clinical characteristics and the carrier state. Pediatrics. 2004:114:1212-9.

12. Lloyd CAC, Jacob SE, Menon T. Pharyngeal carriage of group A streptococci in school children in Chennai. Indian J Med Res. 2006;124:195-8.

13. Dumre S, Sapkota K, Adhikari N, Acharya D, Karki M, Bista S. Asymptomatic throat carriage rate and antimicrobial resistance pattern of Streptococcus pyogenes in Nepalese school children. Kathmandu Univ Med J. 2009;7(28):392-6.

14. Fatima F, Shubha S. Prevalence survey for assessing intensity of group a beta hemolytic Streptococci (GABHS) Subclinical infection rate in school children: a cross sectional study. Glob J Med Res. 2013;13(3):1-6.

15. Ozturk E, Yavuz T, Kaya D, Yucel M. The rate of asymptomatic throat carriage of Group A Streptococcus in school children and associated ASO titers in Duzce. Turkey. Jpn J Infect Dis. 2004;57:271-2.

16. Gheni Al. Detection of Streptococci in the throat swabs from upper respiratory tract infections in Kurdistan Region. J Life Sci. 2014;8(3):283-9.

17. Agency HP. UK standards for microbiology investigations. Identification of Streptococcus species, Enterococcus species and morphologically similar organisms. UK: Standards Unit; 2011. p. 1-22.

18. WHO. Basic laboratory procedures in clinical bacteriology. In: J. Vandepitte et al. 2nd ed. Geneva: Switzerland: WHO; 2003. p. 1-188.

19. Mzoughi R, Selmi H, Ben Said H, Essoussi AS, Jeddi M. Group A streptococci in children with acute pharyngitis in Sousse, Tunisia. East Mediterr Health J. 2004;10:488-93.

20. Sadoh AE, Omokhodion SI. Streptococcal throat isolates in school children in an urban centre in Nigeria-are there other rheumatogenic strains? Niger J Cardiol. 2007;4:50-5.

21. Braito A, Galgani I, Mohammed MR, lozzi C, Ame SM, Haji HS, et al. Epidemiology of Streptococcus Group A in school aged children in Pemba. East Afr Med J. 2004;81:307-13.
22. Gür E, Akkus S, Arvas A, Güzeloz S, Can G, Diren S, et al. Prevalence of positive throat cultures for Group A beta-hemolytic streptococci among school children in Istanbul. Indian Pediatr. 2002;39:569-73.

23. McDonald MI, Towers RJ, Andrews RM, Benger N, Currie BJ, Carapetis JR. Low rates of streptococcal pharyngitis and high rates of pyoderma in australian aboriginal communities where acute rheumatic fever is hyperendemic. Clin Infect Dis. 2006;43:683-9.

24. Kumar R, Vohra H, Chakraborty A, Sharma YP, Shah B, Dhanda V. Epidemiology of group A streptococcal pharyngitis \& impetigo: a cross-sectional \& follow up study in a rural community of northern India. Indian J Med Res. 2009;130:765-71.

25. Al-Gabban N, Al-Ani WA, Al-Kinany BJ. B-Haemolytic streptococcal carrier among school age children. Iraqi J Community Med. 2008;21(2):91-5.

26. Prajapati A, Rai SK, Mukhiya RK, Karki AB. Study on carrier rate of Streptococcus pyogenes among the school children and antimicrobial susceptibility pattern of isolates. Nepal Med Coll J. 2012;14(3):169-71.

27. Danchin MH, Rogers S, Kelpie L, Selvaraj G, Curtis N, Carlin JB, et al. Burden of acute sore throat and Group A Streptococcal pharyngitis in schoolaged children and their families in Australia. Pediatrics. 2007;120:950-7.

28. Nayiga I, Okello E, Lwabi P, Ndeezi G. Prevalence of group a streptococcus pharyngeal carriage and clinical manifestations in school children aged 5-15 yrs in Wakiso District, Uganda. BMC Infect Dis. 2017;17:248.

29. Rubio-López V, Valdezate S, Álvarez D, Villalón P, Medina MJ, Salcedo C, et al. Molecular epidemiology, antimicrobial susceptibilities and resistance mechanisms of Streptococcus pyogenes isolates resistant to erythromycin and tetracycline in Spain (1994-2006). BMC Microbiol. 2012;12(215):1-11.

30. Rijal K, Dhakal N, Shah R, Timilsina S, Mahato P, Thapa PS, et al. Antibiotic susceptibility of Group A Streptococcus isolated from throat swab culture of school children in Pokhara, Nepal. Nepal Med Coll J. 2009;11(4):238-40.

31. Ksia S, Smaoui H, Kechrid A, Bouvet A. Streptococcus pyogenes isolated in a Tunisian pediatric population: emm types, $T$ types, virulence factors and genes of resistance to macrolide and tetracycline. Malay J Microbiol. 2013;9(1):24-32.

32. Ibrahim SB, El-Sokkary R, Elhewala AA, El-Anwar MW, Awad WM, Hamed $M A$, et al. Emerging resistance to erythromycin and penicillin among Streptococcus pyogenes isolates in Zagazig, Egypt. Int J Curr Microbiol App Sci. 2014;3(10):750-6.

33. Graydon C, McKay R, Patrick D. Antimicrobial resistance trends in the Province of British Columbia. British Columbia Communicable Disease Prevention and Control Services Centre for Disease Control. 2011 AMR trends report, www.bccdc.ca. 2011. p. 1-88.

34. Devi U, Borah PK, Mahanta J. The prevalence and antimicrobial susceptibility patterns of beta-hemolytic streptococci colonizing the throats of schoolchildren in Assam, India. J Infect Dev Ctries. 2011;5(11):804-8.

\section{Publisher's Note}

Springer Nature remains neutral with regard to jurisdictional claims in published maps and institutional affiliations.

\footnotetext{
Ready to submit your research? Choose BMC and benefit from:

- fast, convenient online submission

- thorough peer review by experienced researchers in your field

- rapid publication on acceptance

- support for research data, including large and complex data types

- gold Open Access which fosters wider collaboration and increased citations

- maximum visibility for your research: over $100 \mathrm{M}$ website views per year
}

At BMC, research is always in progress.

Learn more biomedcentral.com/submissions 